\title{
PERANAN PEMERINTAH DESA TERHADAP PENGELOLAAN BADAN USAHA MILIK DESA BINA BARU KACAMATAN KULO KABUPATEN SIDENRENG RAPPANG
}

\author{
1)Dedi sudirman, ${ }^{2}$ Monalisa Ibrahim, ${ }^{3)}$ Erfina \\ Fakultas ilmu sosial dan ilmu politik, Universitas Muhammadiyah Sidenreng Rappang \\ dedisudirman43172032inter@gmail.com \\ monalisa2231@yahoo.com \\ erfina.erul85@gmail.com
}

\begin{abstract}
Abstrak
Penelitian ini bertujuan untuk mengetahui pemerintah desa tentang pengelolaan badan usaha milik desa di Desa Kecamatan Bina Baru Kulo Kabupaten Sidenreng Rappang. Populasi dalam penelitian ini adalah 266 Kepala Keluarga di Desa Bina Baru Kecamatan Kulo Kabupaten Sidenreng Rappang. Penelitian ini menggunakan rumus Slovin hingga sampel sebanyak 73 orang berdasarkan data dengan teknik insidental sampling . deskriptif kuantitatif adalah jenis penelitian yang digunakan oleh penelitian ini. Penelitian ini menggunakan teknik pengumpulan data adalah observasi, angket, wawancara dan studi pustaka. Teknik analisis data yang digunakan menggunakan bantuan program IBM SPSS statistic 21.0 Hasil penelitian ini menunjukkan bahwa peran pemerintah desa $48.9 \%$ kurang baik. Pengelolaan Usaha Milik Desa di Desa Bina Baru Kecamatan Kulo Kabupaten Sidenreng Rappang 47.9\% Kurang Baik Peran Pemerintah Desa "Berpengaruh / Penting" Terhadap Pengelolaan Usaha Milik Desa di Desa Bina Baru Kecamatan Kulo Kabupaten Sidenreng Rappang dengan nilai $t$ tabel $t$ tabel $(4,980>1,66660)$ dengan persentase pengaruh 50,9\% kurang baik, sehingga Peran Pemerintah Desa dalam Pengelolaan Badan Usaha Milik Desa di Desa Bina Baru Kecamatan Kulo Kecamatan Sidenreng Rappang belum efektif.
\end{abstract}

Kata kunci : peranan pemerintah desa dan pengelolaan

\begin{abstract}
This study aims to determine the village government about the management of village-owned enterprises in the village of Bina Baru Kulo District, Sidenreng Rappang Regency. The population in this study were 266 heads of families in Bina Baru Village, Kulo District, Sidenreng Rappang Regency. This study uses the Slovin formula to a sample of 73 people based on data with incidental sampling techniques. Quantitative descriptive is the type of research used by this research. This research uses data collection techniques, namely observation, questionnaires, interviews and literature study. The data analysis technique used is the assistance of the IBM SPSS statistic 21.0 program. The results of this study indicate that the role of the village government is $48.9 \%$ less good. Management of Village-Owned Enterprises in Bina Baru Village, Kulo District, Sidenreng Rappang Regency 47.9\% Poor Role of Village Government "Influential / Important" on Village-Owned Business Management in Bina Baru Village, Kulo District, Sidenreng Rappang District with $t$ table $t$ table value $(4,980>1,66660)$ with a percentage of influence of $50.9 \%$ is not good, so that the role of the village government in the management of village-owned enterprises in Bina Baru Village, Kulo District, Sidenreng Rappang District has not been effective.
\end{abstract}

Key words: the role of village government and management

JIA | Volume 9 | Nomor 2 | Edisi Agustus 2021 


\section{A. PENDAHULUAN}

Pemerintahan

Desa merupakan pemerintahan terendah dalam kelembagaan negara dan diatur dalam peraturan tentang desa UU No. 6 Tahun 2014 tentang Desa, desa memiliki peluang yang besar untuk mengelola atau menyelenggarakan pemerintahan sendiri, dan penyelenggaraan pembangunan diharapkan dapat meningkatkan kualitas hidup dan memajuhkan atau meningkatkan kesajatraan msyarakat desa, selain itu pemerintah desa juga diharapkan dapat memberikan perubahan. yang berdampak positif bagi desa, penglolaan pemerintah lebih mandiri dan berbagai sumber daya alam yang dimiliki, termasuk kekayaan milik desa dan pengelolaan keuangan. Peran yang diterima desa sangat besar, tentunya tanggung jawab pemerintah desa sangat besar.

Kewenangan untuk mengatur dan mengurus kepentingan warganya dalam segala ha di desa, baik dalam pelayanan (kepentingan umum), pengaturan (regulasi publik), dan pemberdayaan masyarakat (pemberdayaan). Peran pemerintah desa sangat dibutuhkan dalam berbagai macam jenis kehidupan masyarakat, inovasi-inovasi baru dan perhatian pemerintah desa terhadap infrastruktur pedesaan juga sangat dibutuhkan untuk mewujudkan pembangunan yang utuh. Desa sebagai salah satu pimpinan organisasi pemerintahan dalam menyukseskan urusan pemerintahan bersumber dari pemerintah pusat.

Pemerintah Desa dalam rangka mewujudkan kemajuan dari aspek ekonomi perlu melirik Undang-undang desa yang mengatur adanya Badan Usaha Milik Desa (BUMDes), adanya lembaga ini akan mewujudkan suatu desa yang lebih mandiri. Kebebasan yang dimaksud adalah proses yang dilakukan oleh pemerintah dan masyarakat desa untuk melaksanakan dalam suatu aktivitas memenuhi kebutuhannya sendiri-sendiri. Hal ini sesuai dengan amanat tentang pemerintah Daerah yang menyatakan bahwa " Desa dapat membentuk badan usaha sesuai dengan potensi dan kebutuhan desa ".32 Tahun 2004. Pendirian BUMDes juga penting dan dijelaskan dalam Peraturan Pemerintah tentang Desa, yang menyatakan bahwa "untuk meningkatkan pendapatan desa dan masyarakat, Pemerintah Desa dapat mendirikan BUMDes sesuai dengan kebutuhan dan potensi desa
Nomor 72 Tahun 2005. ". Amanat dalam kedua peraturan tersebut menyebutkan bahwa pendiroian sebuah BUMDes harus didasarkan pada suatu kebutuhan, potensi, dan kemampuan desa untuk meningkatkan kesejahteraan masyarakat.

Menurut Permendagri No. 39 Tahun 2010 tentang BUMDes adalah Usaha Desa yang dibentuk yang kepemilikan dan pengelolaan modalnya dilakukan oleh masyarakat dan Pemerintah Desa. BUMDes adalah dibentuk untuk upaya memperkuat perekonomian dan dibentuk berdasarkan kebutuhan dan potensi desa. Peraturan Daerah Kabupaten Sidenreng Rappang Nomor 13 Tahun 2016 Pasal (tiga) 3, pada prinsipnya BUMDes dibentuk oleh pemerintah desa dengan tujuan untuk: a) memajukan taraf perekonomian masyarakat desa; b) pengelolan potensi ekonomi desa dapat mengoptimalkan aset desa agar bermanfaat bagi kesejahteraan desa; c) Meningkatkan upaya masyarakat dalam; d) menyusun rencana kerjasama bisnis antar desa dan / atau dengan pihak ketiga atau lebih; e) peluang pasardapat diciptakan dan jaringan yang mendukung kebutuhan pelayanan publik masyarakat; f) membuat peluang kerja; g) memajukan kesejahteraan masyarakat desa melalui peningkatan pelayanan publik, perkembangan dan menyamaratakan perekonomian masyarakat desa; dan h) Meningkatkan pendapatan Asli Desa dan pendapatan masyarakat desa

Pemerintah desa dalam pengelolaan Badan Usaha Milik Desa (BUMDes) dimana secara umum mempunyai tujuan awal didirikannya BUMDes bertujuan untuk mengakomodir dan mendorong segala kegiatan dalam memajukan pendapatan masyarakat desa dan kegiatan ekonomi yang perlu dikelola oleh masyarakat desa. sendiri dengan bantuan kepala desa sebagai patronase dalam membangun usaha. Sebagai usaha desa, pendirian BUMDes diharapkan dapat memaksimalkan potensi masyarakat dari segi ekonomi, sumber daya alam dan sumber daya manusia sehingga dapat diurus dengan sebaik-baiknya untuk kehidupan masyarakat sehingga masyarakat desa bisa menjadi mandiri. dan berkembang lebih baik dalam meningkatkan kehidupan sosial.

Menurut Nordholt dkk (2007) mengemukakan bahwa peranan pemerintah dalam pengelolaan Badan Usaha Milik Desa 
memiliki peranan yakni sebagai motivator, fasilitator, dan mediator. Dilihat dari teori di atas yang mengenai peranan pemerintah desa dalam pengembangan masyarakat, melalui perogram BUMDes, namun yang terjadi BUMDes yang ada di Desa Bina Baru tidak berjalan sesuai yang diharapkan, hal tersebut di kerenakan diduga kurangnya perhatian, baik itu dalam memotivasi, memfasilitasi, dan memberikan media, dalam mengelolaan BUMDes.

Peraturan Daerah Kabupaten Sidenreng Rappang Nomor 13 Tahun 2016 Pasal (tiga) 3, tujuan didirian/dibentuknya BUMDes calon peneliti melihat tidak terlaksananya peraturan Daerah di Desa Bina Baru kacamatan Kulo, dari observasi awal bahwa dilihat dari beberapa desa yang memiliki BUMDes yang ditujukan untuk meningkatkan kesejahteraan masyarakat, namu BUMDes yang ada di Desa Bina Baru tidak berjalan semestinya dikarenakan pengurus BUMDes yang tidak aktif dan anggaran yang disediakan oleh pemerintah desa sebanyak Rp. 80.000.000., di Tahun 2019 namun tidaknya ada program yang dilaksanakan. Berdasarkan hasil wawancara dalam kegiatan Magang Angkatan Pertama Universitas Muhammadiyah Sidenreng Rappang selama satu bulan ditemukan bahwa Badan Usaha Milik Desa (BUMDEs) tidak berjalan sesuai yang diharapkan, calon peneliti menduga ini karena kurangnya perhatian dari pemerintah desa terhadap pengelolaan Badan Usaha Milik Desa (BUMDes), sehingga peran pemerintah masih belum optimal sehingga Badan Usaha Milik Desa (BUMDes) tidak berjalan sesuai yang diharapkan.

Padahal tujuan didirikannya Badan Usaha Milik Desa (BUMDes) sesuai di isi Peraturan Daerah Kabupaten Sidenreng Rappang Nomor 13 Tahun 2016 Pasal (tiga) 3 pada dasarnnya BUM Desa didirikan oleh pemerintah desa,untuk agar bisa meningkatkan perekonomian, pedapatan, dan meningkatkan potensi desa secara mandiri dalam meningkatkan kesejatraan masyarakat yang ada di Desa Bina Baru

\section{B. METODE PENELITIAN}

Penelitian ini diharapkan lebih terarah dengan tujuan yang di harapkan. Dimana dasar penelitian ini Kuantitatif yaitu dengan membuktikan teori dan konsep yang digunakan sesuai realitas yang ada dengan melalui pencarian informasi / data. Populasi dalam penelitian ini adalah masyarakat desa Bina Baru Kacamatan Kulo Kabupaten Sidenreng Rappang sebanyak 266 orang. Adapun sampel dalam penelitian ini menggunakan rumus sloving sebanyak 73 orang. Dalam penelitian ini Teknik pengumpulan data yang digunakan adalah melalui ovservasi, koesioner, wawancara, dan studi pustaka.

\section{HASIL DAN PEMBAHASAN}

Peranan Pemerintah Desa di Desa Bina Baru Kacamatan Kulo kabupaten Sidenreng Rappang meliputih : Motivator, Fasiloitator, Mediator. Berdasarkan hasil persentase rata-rata dari 3 indikator pada variabel peranan pemerintah desa maka hasil rata-rata persentase yang di peroleh sebesar 48,9 dan dinyatakan bahwa hal tersebut masuk dengan kategori kurang baik, hal ini berarti kurang dari 100\% yang harus dicapai, namun terdapat $51,1 \%$ persentase yang tidak tercapai. Yang seharusnya dicapai sehingga dikatakan bahwa peranan pemerintah desa di Desa Bina Baru Kacamatan Kulo Kabupaten Sidenreng Rappang berada pada kategori kurang baik.

Pengelolaan Badan Usaha Milik Desa di Desa Bina Baru Kacamatan Kulo Kabupaten Sidenreng Rappang meliputi : Kooperatif, Partisipatif, Emansipatif, Transparan, Akuntabel, dan Sustainabel. Hasil rata-rata persentasi mengakumulasi dari 6 indikator pada variabel pengelolaan, maka hasil rata-rata persentase yang di peroleh sebesar 47,9. Pengelolaan Badan Usaha Milik Desa yang seharusnya tercapai $100 \%$ namun terdapat $52,1 \%$ persentase yang tidak tercapai. Yang seharusnya dicapai sehingga pengelolaan Badan Usaha Milik Desa di Desa Bina Baru Kacamatan Kulo Kabupaten Sidenreng Rappang berada pada kategori kurang baik

Berdasarkan Nilai $\mathrm{t}$ hitung $\geq \mathrm{t}$ tabel atau $4,980 \geq 1,66660$ Maka Ho ditolak dan $\mathrm{Ha}$ diterima yang berarti berpengaruh signifikan, artinya peranan pemerintah desa berpengaruh signifikan terhadap pengelolaan badan usaha milik desa di Desa Bina Baru Kacamatan Kulo Kabupaten Sidenreng Rappang. 


\section{KESIMPULAN}

Berdasarkan dari hasil penelitian pada bab sebelumnya yang telah diuraikan, maka dapat disimpulkan bahwa:

1. Peraanan pemerintah desa terhadap pengelolaan badan Usaha Milik Desa di Desa Bina Baru Kacamatan Kulo Kabupaten Sidenreng Rappang meliputi a). Motivator $52,2 \%$, b). Fasilitator $46,4 \%$, dan c). Mediator 48,2\%, berdasarkan hasil penelitian dengan analisis distribusi frekuensi pada variabel $X$ (Peranan Pemerinta Desa) maka diperoleh rata-rata persentase $48,9 \%$ atau pada kategori kurang baik atau tidak efektif.

2. Pengelolaan badan usaha milik desa meliputi: a). Kooperatif 52,2\%, b). Partisispatif 43,8\%, c). Emansipatif 47,2\%, d). Transparan $53 \%$, e). Akuntabel $44,8 \%$, dan f). Sustanibel 46,8\%. Berdasar padahasil penelitian dengan analisis distribusi frekuensi pada variabel $Y$ (Pengelolaan Badan Usaha Milik Desa) maka di peroleh rata-rata berada pada persentase 47,9 atau berada pada kategori kurang baik atau belum efektif.

3. Berdasarkan model summary $r$ square $=$ 0,509 yang artinya peranan pemerintah desa (X) berpengaruh sebesar 50,9\% terhadap pengelolaan badan usaha milik desa, adapun sisanya sisanya yaitu $49,1 \%$ yang dipengaruhi oleh variabel lain yang tidak masuk dalam konsep penelitian ini.

\section{E. DAFTAR PUSTAKA}

Ade Eka Kurniawan. (2016). Peranan Badan Usaha Milik Desa (Bumdes) Dalam Peningkatan Pendapatan Asli Desa (Desa Lanjut Kecamatan Singkep Pesisir Kabupaten Lingga Tahun 2015). Fakultas IImu Sosial Dan IImu Politik Universitas Maritim Raja Ali Haji, 33. Retrieved From

Http://Jurnal.Umrah.Ac.Id/Wp-

Content/Uploads/Gravity_Forms/1Ec61c9cb232a03a96d0947c6478e525e /2016/08/Jurnal-Adhe.Pdf

Agusliansyah, K. (2016). Peran Kepala Desa Dalam Pengelolaan Badan Usaha Milik Desa ( Bumdes ) Di Desa Jemparing. 4(4), 1785-1796.
e-ISSN 2723-0201

Ahmad, J. (2015). Metode Penelitian Admistrasi Publik Teori Dan Aplikasi. Yogyakarta: Gava Media.

Andjarwati, T., Maslow, H. K., Gregor, T. X. Y. M., Motivasi, T., \& Mcclelland, P. (2015). Motivasi Dari Sudut Pandang Teori Hirarki Kebutuhan Maslow, Teori Dua Faktor Herzberg, Teori X Y Mc Gregor, Dan Teori Motivasi. 1(1).

Emanuel Runiuk Kunja1, Agustinus Longa Tiza2, F. A. (2019). Peranan Pemerintah Desa Dalam Pengelolaan Badan Usaha Milik Desa (Bumdes) Di Desa Fafinesu C Kecamatan Insana Fafinesu Kabupaten Timor Tengah Utara. 1(April), 26-40.

Fitrianda, M. I. (2013). Digital Digital Repository Repository Universitas Universitas Jember Jember Digital Digital Repository Repository Universitas Universitas Jember.

Goleman Et Al., 2019. (2019). Landasan Teori Administrasi. Journal Of Chemical Information And Modeling, 53(9), 16891699.

Han, E. S., \& Goleman, Daniel; Boyatzis, Richard; Mckee, A. (2019). 済無no Title No Title. Journal of Chemical Information And Modeling, 53(9), 16891699.

Hashimoto-Hill, S. Et Al. (2011). 済無no Title No Title. Journal of Chemical Information And Modeling, 53(9), 16891699.

Husniyawati, Y. R., \& Wulandari, R. D. (2016). Analisis Motivasi Terhadap Kinerja Kader Posyandu Berdasarkan Teori Victor Vroom. Jurnal Administrasi Kesehatan Indonesia, 4(2), 126. Https://Doi.Org/10.20473/Jaki.V4i2.201 6.126-135

li. (2015a). Mediasi (Tahkim) Sebagai Penyelesaian Tindak Pidana Pembunuhan. 12(1), 18-39.

Ii, B. A. B. (2015b). Landasan Konsep Dan Teori. 8-14.

Irfan Nopandi Ismail, M. R. R. R. (N.D.). Peranan Kepemimpinan Kepala Desa 
Terhadap Penyelesaian Konflik

Sengketa Tanah Di Desa Cemba Kecamatan Enrekang. 8, 57-63.

Koso, J., Ogotan, M., \& Mambo, R. (N.D.). Manajemen Pengelolaan Badan Usaha Milik Desa.

Laru, F. H. U., \& Suprojo, A. (2019a). Peran Pemerintah Desa Dalam Pengembangan Badan Usaha Milik Desa (Bumdes). Jisip: Jurnal IImu Sosial Dan IImu Politik, 8(4), 367-371. Retrieved From Https://Publikasi.Unitri.Ac.Id/Index.Php/ Fisip/Article/View/2017

Laru, F. H. U., \& Suprojo, A. (2019b). Peran Pemerintah Desa Dalam Pengembangan Badan Usaha Milik Desa (Bumdes). Jisip: Jurnal IImu Sosial Dan IImu Politik, 5(2), 59-63. Retrieved From Https://Publikasi.Unitri.Ac.Id/Index.Php/ Fisip/Article/View/2017

Nu'mang, A. M. A. (2014). Peranan Pemerintahan Terhadap Implementasi Penanggulangan Dan Pencegahan Narkoba Di Kecamatan Maritengngae Kabupaten Sidenreng Rappang. 8, 1-7. Nursalam, 2016, Metode Penelitian, \& Fallis, A. . (2013). 済無no Title No Title. Journal Of Chemical Information And Modeling, 53(9), 1689-1699.

Prasetyo, R. A. (2016). Peranan Bumdes Dalam Pembangunan Dan Pemberdayaan Masyarakat Di Desa Pejambon Kecamatan Sumberrejo Kabupaten Bojonegoro. Jurnal Dialektika, Xi(1), 86-100.

Prawira, P. A. (2012). Psikologi Pendidikan Dalam Perspektif Baru. Ar-Ruzz Media, 320.

Soares, A., Nurpratiwi, R., \& Makmur, M. (2015). Peranan Pemerintah Daerah Dalam Perencanaan Pembangunan Daerah. 4(2), 231-236.

Suharyanto, Rossana, M. B. (2014). Pengembangan Dan Pengelolaan Bum Des.
Sulistyono, N. Y. (2013). Ekonomi. Repository.Upi.Edu 19, 19-29.

Supriyanto. (2019). Implementasi Kebijakan Pemerintah Terhadap Pengelolaan Badan Usaha Milik Desa Di Desa Bulo Wattang Kecamatan Panca Rijang Kabupaten Sidenreng Rappang.

T Keban, Y. (2008). Enam Dimensi Strategis Administrasi Publik (P. 305). P. 305.

Villela, Lucia Maria Aversa. (2013). Peran Pemerintah Desa Dalam Pengelolaan Badan Usaha Milik Desa (Bumdes). Journal Of Chemical Information And Modeling, 53(9), 1689-1699. 